\title{
Crítica IDEOLÓgICA SOBRE PRODUCCIÓN DE VIVIENDA PARA SECTORES SUBALTERNOS EN ARgENTINA: CAMPO Y CIUDAD EN CONTRAPUNTO
}

\section{Ideological Criticism on Housing Production for Subaltern Sectors in Argentina: the Countryside and the City as Counterpoints}

\section{María Eugenia Boito* Cecilia Mercedes Quevedo ${ }^{\star *}$}

Resumen: Desde un ejercicio de crítica ideológica, el artículo compara la producción de la vivienda social para sectores subalternos en dos provincias de Argentina en el periodo 2003-2015. Se analizan las experiencias de los jóvenes sobre los nuevos espacios de habitabilidad en contextos hegemónicos de expansión de las formas de consumo. El objetivo del trabajo busca deconstruir la producción ideológica del acceso al hábitat social dentro de un proceso de ampliación de la agricultura capitalista a gran escala y de retóricas inclusivas para sectores subalternos. La crítica ideológica se constituye en una apuesta de la escritura científica que posibilita unir sentidos sobre lo que aparece geográfi-

\footnotetext{
* Doctora en Ciencias Sociales, Universidad de Buenos Aires. Licenciada en Comunicación Social, Universidad Nacional de Córdoba, Universidad Nacional de Córdoba, Argentina. Investigadora Adjunta, Consejo Nacional de Investigaciones Científicas y Técnicas, Consejo Nacional de Investigaciones Científicas y Técnicas. Docente de la Facultad de Comunicación, UNC. Temas de interés: las estructuras de sentir/estructuras de experiencia, de las clases subalternas en contextos de mediatización y mercantilización, correo e.: meboito@yahoo.com.ar

** Doctora en Ciencia Política, Universidad Nacional de Córdoba. Licenciada en Ciencia Política, Universidad Nacional de Villa María. Investigadora Asistente, Consejo Nacional de Investigaciones Científicas y Técnicas. Temas de interés: las construcciones ideológicas de la política habitacional para pueblos indígenas en provincia de Chaco, Argentina, http://orcid. org/0000-0001-6964-1349, correo e.: quevedoceci@gmail.com Fecha de recepción: 0202 18; 2a. versión: 1107 18; Fecha de aceptación: 160718.
}

(cc) EY-NC-ND Páginas 111-142. 
camente como fragmentado en las experiencias sociales del campo y la ciudad. Metodológicamente, el artículo utiliza datos del trabajo de campo obtenidos en los espacios culturales comparados.

Palabras clave: hábitat social, estructura de sentir, experiencia, jóvenes, capitalismo.

Abstract: From an exercise of ideological criticism, the article compares the production of social housing for subaltern sectors in two provinces of Argentina in the period 2003-2015. The experiences of young people concerning the new spaces of habitability in hegemonic contexts of expansion of the forms of consumption are analyzed. The objective of this paper seeks to deconstruct the ideological production of access to social habitat within a process of large scale expansion of capitalist agriculture and an inclusive rhetoric for subaltern sectors. Ideological criticism constitutes a commitment to scientific writing that makes it possible to unite senses about what appears geographically as fragmented in the social experiences of the countryside and the city. Methodologically, the article uses data from fieldwork obtained in the compared cultural spaces.

Keywords: social housing, feeling structure, experience, youth, capitalism. 


\section{Obertura}

En el presente artículo comparamos la producción ideológica de la vivienda social para sectores subalternos en dos provincias de Argentina. Indagamos experiencias sociales en espacios culturales de regiones heterogéneas tomando como instancias de materialización del sentir las expresiones de los jóvenes en nuevas condiciones de habitabilidad. Nuestras reflexiones toman por objeto la implementación de dos programas de hábitat social durante la última década del estado de bienestar en Argentina. ${ }^{1}$ Nos referimos a los programas Mi casa, mi vida, en la ciudad de Córdoba, y Mejor Vivir, en el noroeste de la provincia de Chaco. La producción de experiencia social en dos lugares distintos/ distantes conjugan puntos en común resultado de desigualdades socioespaciales y de una misma lógica del capital: por un lado, los desplazamientos a "ciudades-barrio" resultado de procesos de sociosegregación urbana $^{2} \mathrm{y}$, por otro lado, los procesos de urbanización de poblaciones indígenas de contextos rurales en pequeñas localidades.

En la provincia de Córdoba, la ciudad capital se caracteriza por su tradición industrial actualmente en retroceso. En los últimos años, con el auge del precio internacional de los commodities, los excedentes de la producción del monocultivo de soja fueron ubicados en inversiones inmobiliarias en esta ciudad. ${ }^{3}$ A nivel urbanístico estas inversiones

\footnotetext{
${ }^{1}$ El recorte temporal del artículo en el periodo 2003-2015 coincide con el gobierno nacional, identificado con el partido Frente para la Victoria — partido que recupera retóricas igualitarias del movimiento peronista de la década de 1940 — que implementa políticas sociales diversas. En las elecciones de 2015, el cambio del signo político del gobierno, con el partido Cambiemos, se inscribe en un perfil neoliberal caracterizado por la retracción del gasto público en áreas sociales. ${ }^{2}$ En Argentina, los estudios sobre transformaciones urbanas y procesos de sociosegregación en contextos metropolitanos tienen su referente en los abordajes precursores de Hilda Herzer (2012). Los equipos de trabajo de esta autora discuten la noción anglosajona de "gentrificación", advirtiendo rasgos singulares en el ámbito metropolitano, como en la ciudad de Buenos Aires. ${ }^{3}$ La región centro-sur de la provincia de Córdoba forma parte de la región denominada Pampa húmeda que, por la fertilidad de los suelos, se desenvuelven agriculturas vinculadas al agronegocio. No obstante, la producción de soja también es una de las actividades primarias que se desarrollan desde los últimos tiempos en el área centro-sur de la provincia de Chaco a pesar del tipo de suelo propio del Chaco austral —área de monte, clima seco y suelo arcilloso-. En efecto, en Argentina la frontera agropecuaria de la producción de soja se encuentra ligada al agrobussines (Gras y Hernández, 2009) dentro de un proceso latinoamericano generalizado de reprimarización de las economías.
} 
depararon el aumento de la renta del suelo urbano en nuevas tierras disponible y reconfiguraciones de barrios tradicionales reorientados hacia el turismo. En este primer escenario nos encontramos con mecanismos de socio-segregación social de sectores populares a partir de la construcción de "ciudades-barrio" en áreas periféricas de la ciudad de Córdoba.

En la provincia de Chaco, por otro lado, focalizamos en las dinámicas territoriales en El Impenetrable, región geográfica y poblacional con características propias a las provincias periféricas del norte argentino. En este territorio, el contexto de monte posibilitó actividades forestales y luego producción de algodón, actividad actualmente en tecnificación. Históricamente, la población indígena ocupó allí el lugar de semiproletariado junto con otros sectores subalternos. En este segundo escenario, desde la última década el ámbito ruralizado es reconfigurado a partir de la erradicación de "viviendas-rancho" 5 , la construcción de viviendas en áreas urbanizadas y el otorgamiento de políticas sociales.

El trabajo posee una estructura sonoro-argumentativa en tres apartados. En primer lugar, para comprender las transformaciones y dinámicas de los procesos culturales estructuramos un abordaje teórico-metodológico desde las perspectivas de Slavoj Žižek y Raymond Williams. En segundo lugar, reconstruimos algunos elementos estructurales en Argentina que posibilitan comprender una perspectiva anclada en la idea de "totalidad abierta" (Lefebvre,

\footnotetext{
${ }^{4}$ Las "ciudades-barrio" son nuevos barrios construidos por la política de hábitat social Mi casa, mi vida, implementada por el gobierno de la provincia de Córdoba desde el año 2004. Desde nuestra línea de investigación consideramos las ciudades-barrio como entornos de clase por formar parte de procesos de segregación hacia áreas periféricas (Boito y Espoz, 2014). En este sentido, la noción de "socio-segregación" que utilizamos se fundamenta en la localización y los efectos de los procesos habitacionales en Córdoba (véase, como ejemplo, Scribano y Boito, 2010; Scarponetti y Ciuffolini, 2011; Boito y Espoz, 2014).

${ }^{5}$ Las "viviendas-rancho" son categorías estatales y propias de censos poblacionales basadas en ciertos indicadores de precariedad — propios de áreas rurales, paredes de adobe, piso de tierra, techo de paja o chapa, etc.- - Las poblaciones indígenas que habitan el territorio chaqueño han estado vinculadas a prácticas de construcción distintas a materiales industriales. Sus viviendas, generalmente de adobe y ramas de árboles, fueron atravesadas por discursos sanitaristas que advierten riesgos sociales y transmisión de vectores — mal de Chagas, por ejemplo-. Postulamos que los procesos de sedentarización de la población indígena de las etnias qom y wichí han estado históricamente acompañados de la moralización del hábitat desde criterios occidentales y urbanos de la vivienda (Quevedo, 2015).
} 
2011) en el vínculo dialéctico entre lo rural y lo urbano a propósito de alteraciones en la organización del espacio (Limonad y MonteMór, 2012). Por último, mostramos resultados y discusiones relativas a los dos espacios culturales seleccionados remitiendo a las vivencias que experimentan los jóvenes en nuevas condiciones de habitabilidad. En este sentido, para la interrogación de la dimensión sensible de las prácticas, metodológicamente utilizamos notas de campo, imágenes y entrevistas. En el cierre del trabajo, proponemos suspender la melodía ideológica/canción de cuna sobre la habitabilidad en tanto progreso de los pobres.

\section{Aspectos teórico-metodológicos:}

\section{crítica ideológica y experiencia en sociedades capitalistas}

En trabajos previos hemos explorado la dimensión conflictiva y vivencial con la que operan los programas habitacionales en contexto de sociosegregación de la ciudad de Córdoba desde dimensiones cualitativas y cuantitativas (Boito y Espoz, 2014; Boito y Seveso Zanin, 2015). Estos abordajes han permitido construir una matriz de inteligibilidad y análisis en pos de precisar teóricamente una perspectiva materialista sobre las sensibilidades sociales en contextos urbanos (Boito, 2010; Espoz, 2013). En estas investigaciones empíricas la noción de "ideología” de Žižek (2009), articulando una comprensión materialista con el psicoanálisis lacaniano, es fundamental en términos teóricometodológicos. Nos referimos al ejercicio crítico sobre aquella matriz que regula lo visible/invisible y activa facetas de la violencia ética en el capitalismo contemporáneo. En este sentido, para analizar las nuevas subjetividades en sociedades como las nuestras, la perspectiva de Žižek (2009) posibilita deconstruir lo que aparece como síntoma en formaciones sociales. Es decir, aquello que es reprimido bajo retóricas políticas igualitaristas de sociedades democráticas es lo que retorna y refiere a las formas de la desigualdad estructural.

La figura que encontramos para escenificar la complejidad del modelo socio/cultural productivo es la categoría musical de la polifonía que caracteriza la ejecución del contrapunto. La crítica ideológica (Žižek, 2009) se constituye en una apuesta de la escritura científica y la con- 
vocatoria a unir sentidos sobre lo que aparece geográficamente como fragmentado. Más que una opacidad sonora al son del progreso de los pobres, el ejercicio de reflexión sobre las reconfiguraciones de los espacios culturales permite dimensionar las melodías individuales que se conjugan de manera simultánea en una gran obra. Si la lógica del capital implanta la necesidad de "ver" y "mostrar" los logros de las políticas habitacionales para una ciudadanía incluida en políticas de Bienestar, ${ }^{6}$ aquí proponemos escuchar sus melodías individuales. Eso permite percibir armonías y disonancias en el desarrollo del capital mediante la visibilización de nuevas desigualdades y la alianza entre el Estado - gestor de la obra pública - con empresarios locales de la construcción —en Chaco- o grandes inversores privados — en Córdoba.

En esta oportunidad, proponemos recorrer algunos conceptos centrales de Raymond Williams para precisar nuestro interrogante inicial sobre hábitat social y experiencias subalternas. ${ }^{7}$ Desde esta perspectiva es posible comprender la cultura como elemento configurador de relaciones sociales dentro de procesos económicos y productivos. En primer término, el concepto de "hegemonía" en Williams constituye un proceso activo, en constante transformación, que asume la centralidad de lo superestructural y lo simbólico como momento de instanciación de la dominación. Su significación debe considerarse como un proceso de carácter tan material como lo que ocurre en el plano que identifican las posiciones estructuralistas. Williams no sólo mantiene el carácter clasista, ya precisado por Antonio Gramsci en relación con la noción de hegemonía, sino

\footnotetext{
${ }^{6}$ El modelo de bienestar argentino tuvo políticas habitacionales específicas en cada provincia considerada. En este trabajo nos referimos específicamente a las gobernaciones de José Manuel De la Sota en la provincia de Córdoba — periodos 1999-2007 y 2011-2015- y a Jorge Capitanich en la provincia de Chaco - 2007-2015- En este sentido, partimos de inscribir la particularidad de las políticas habitacionales en las dos formaciones provinciales respecto a procesos metropolitanos —en Buenos Aires, por ejemplo-y las conceptualizaciones respectivas.

${ }^{7}$ Concretamos una relectura que vincula dos obras centrales del pensamiento de Williams: Marxismo y literatura (2000) y El campo y la ciudad (2001). En el contexto inglés de reconfiguración del marxismo estructuralista y no estructuralista, El campo y la ciudad, publicado originalmente en 1973, corresponde al comienzo de un giro en el pensamiento de Williams que alcanza su umbral teórico con Marxismo y literatura, publicado en 1978. En esta constelación teórica próxima a los Estudios Culturales, la categoría "sectores subalternos" la utilizamos como sinónimo de expresiones locales, en cada contexto, en la singularidad de marcadores de clase y etnia — como "indígenas", "pobres" o "sectores populares".
} 
que comprende lo vivencial del sujeto en términos de "experiencia". ${ }^{8}$ Haciendo inteligibles las vivencias cotidianas, la dominación es posible a través de la dimensión hegemónica de los procesos sociales. Estas dinámicas instituyen "estados del sentir" que se configuran en una dialéctica entre las prácticas, las expectativas del actor y las dinámicas de lo estructural, obstaculizando — como en Žižek (2009)— la posibilidad de que el sujeto pueda pensarse en términos de "clase".

Como caso ilustrativo, el problema de la vivienda está relacionado — para el pensador galés - con procesos de dominación hegemónicos y formas de subordinación de clases particulares. La crisis de la vivienda se vincula a los recursos con los que se regula socialmente en determinado espacio-tiempo, aunque opere como una dimensión presente dentro de las relaciones de subordinación capitalista. ${ }^{9}$ De esta forma, impone la fragmentación entre los espacios - el campo y la ciudad-; la distribución física de la habitabilidad —en centro o en periferias; lugares de trabajo o de ocio; ambientes privados y ambientes públicos_; o "estilos de vida" sociales.

Por otra parte, las relaciones entre el campo y la ciudad dentro de la matriz del capitalismo deben comprenderse en vinculación. De este modo, el presuponerse mutuamente es resultado de un proceso histórico y gradual cuyo "contraste entre el campo y la ciudad, como dos estilos fundamentalmente distintos de vida, se remonta a la época clásica” (Williams, 2001: 25). Como expresó Beatriz Sarlo (2001), aquello que denominamos "campo" y "ciudad" constituyen "espacios culturales” más que sociológicos. Son producidos a través del despliegue iconográfico y escenográfico del capitalismo. En esta perspectiva, la

\footnotetext{
8 "La hegemonía constituye todo un cuerpo de prácticas y expectativas en relación con la totalidad de la vida: nuestros sentidos y dosis de energía, las percepciones definidas que tenemos de nosotros mismos y de nuestro mundo. Es un vívido sistema de significados y valores - fundamentales y constitutivos - que en la medida en que son experimentados como prácticas parecen confirmarse recíprocamente ... Es decir que, en el sentido más firme, es una 'cultura', pero una cultura que debe ser considerada asimismo como la vívida dominación y subordinación de las clases particulares" (Williams, 2000: 131-132).

9 "La construcción de viviendas lejos del centro y, en general, la crisis de la vivienda están relacionadas por igual con la distribución de los asentamientos humanos que ha sido el resultado de una serie de decisiones de una minoría sobre dónde deben ubicarse los lugares de trabajo, según criterios de provecho y conveniencia internos" (Williams, 2001: 363).
} 
compleja relación entre el momento estructural y el superestructural de lo hegemónico, el espacio del campo y la ciudad, están intrínsecamente vinculados en tanto ámbitos sociales y simbólicos en transformación. ${ }^{10}$

Para Williams (2000), los modos particulares mediante los que opera el capitalismo sólo pueden ser analizados históricamente, aunque se interpreten sociológicamente a través de un procesamiento cultural de los datos. Metodológicamente, la categoría "estructuras del sentir" constituye una dimensión analítica que, como hipótesis para analizar la configuración cultural en momentos de cambios, posibilita percibir los elementos sociales que no varían o que se transforman. En esta categoría - entendida como horizonte de expectativas y posibilidades imaginarias - encuentra carnadura el componente material de la dimensión simbólica. Al centrarse en conexiones y componentes vivenciales dentro de una temporalidad relativa, las sensibilidades y las experiencias descriptas están siendo intervenidas o trastocadas por la dimensión hegemónica en un determinado espacio-tiempo. En la articulación entre pensamiento/sentimiento y la interrelación entre valores y significados se inscribe la experiencia de la pobreza como "producto social" y resultante de los procesos de producción más amplios. De allí que sea posible analizar las estructuras del sentir en distintos estilos de expresión donde la materialidad de las innovaciones técnicas expone una de las formas en que se transforma la experiencia (Williams, 2011).

En este marco analítico, partimos de considerar que la población juvenil es una franja etaria cuya subjetividad, en términos de expresividad social, se ven sumamente afectadas por las tensiones entre la expansión del consumo y la violencia estructural. Nos apoyamos en "la música, como técnica de registro de las sensibilidades” (Espoz e Ibañez, 2008: 81) y como eje argumentativo dentro del campo de la crítica ideológica en apropiaciones en Argentina (Grüner, 2009; Scribano y Boito, 2010).

10 "He estado sosteniendo que el capitalismo, como modo de producción, es el proceso básico de la mayor parte de lo que conocemos como la historia del campo y la ciudad. Sus impulsos económicos abstractos, sus prioridades fundamentales en lo que respecta a las relaciones sociales, sus criterios de crecimiento, de ganancia y pérdida, han modificado durante varios siglos, nuestro campo y han creado los tipos de ciudades que tenemos hoy. En sus formas finales, como imperialismo, ha terminado por alterar todo nuestro mundo" (Williams, 2001: 371). 
De este modo, configuramos una estrategia analítica para percibir las transformaciones y dinámicas de los procesos culturales con especial atención en la relación entre técnica y sensibilidad. Como estrategia teórica-metodológica nos detenemos en el marco de relaciones en el cual encuentra lugar la operatoria del capitalismo en términos de lo ideológico y lo experiencial, tal como lo exponemos en el próximo apartado.

\section{Capitalismo y coyuntura: abrir la totalidad}

Aquí retomamos algunos elementos contextuales de la última década que posibilitan comprender las políticas de hábitat social abordadas dentro de las políticas de Bienestar y la activación del ideario igualitario inspirado en el primer peronismo. Para ello es necesario considerarlas en la tensión dialéctica entre lo rural/urbano, sus dinámicas y contradicciones dentro de una perspectiva anclada en la idea de "totalidad abierta" (Lefrevre, 2011). Se trata de procesos que se manifiestan en un espacio/tiempo específico y que hemos caracterizado como capitalismo neocolonial (Scribano y Boito, 2010).

En Argentina, el libro Merecer la ciudad... (1991) de Oscar Oszlak fue el referente local que, en periodo de transformación del capital a escala global, analizó el problema de los asentamientos urbanos y la desigualdad en el emergente contexto neoliberal. El trabajo pronosticó el largo derrotero que tendrían los sectores populares en relación con el acceso al hábitat en un momento de crisis estructural, emergencia del Estado excluyente y, desde los años ochenta, agudización del conflicto social. En esos momentos de hegemonía del capital financiero, las ciudades más urbanizadas habían vinculado una noción de bienestar al consumo y, en una sociedad clasista, éste era el diagnóstico principal de una estructura social caracterizada por la agudización de la desigualdad. Mientras que la industrialización europea evidenciaba los efectos trastocando las formas de vida en el campo y la ciudad, en Argentina se vieron impedidas las formas de reproducción material y simbólica del orden social. Los sujetos que iban dejando de pertenecer a la sociedad salarial, como se la había conocido a mitad de siglo XX, eran desplazados de las ciudades capitales, confinados a usurpar asentamientos marginales y responsabilizados de su propio destino en tanto "pobres". 
No obstante, el modelo de acumulación de los últimos años modificó el perfil del Estado argentino tal como se conoció hasta la crisis social de 2001-2002. En el periodo 2003-2015, mutó hacia formas bienestaristas basado en la generación del consumo interno mediante políticas sociales. Las intervenciones del Estado sobre la pobreza tuvieron a la dimensión el hábitat como su programa de “inclusión” más emblemático, expandido y federal. De este modo, la vivienda social ocupa una página en la narrativa de la década analizada, donde la estructuración social estuvo sostenida y soportada en la reproducción ideológica de la ausencia de conflicto social. La activación económica mediante la obra pública y de las políticas de vivienda fue el mecanismo que el estado de bienestar encontró para suturar la contradicción capital-trabajo. A diferencia del periodo del primer peronismo (1946-1955), los diferentes niveles estatales se involucraron en la construcción efectiva de las viviendas amparados en la generación de trabajo, el dinamismo del mercado y las alianzas con sectores empresarios de la construcción. Del mismo modo, la vivienda estatal operó como recurso que permitió la institucionalización y la cooptación de distintos movimientos sociales y organizaciones de base de distintos puntos del país (Svampa, 2008).

En un contexto de reprimarización del capitalismo latinoamericano, el financiamiento de las políticas sociales se configuró a partir de las transformaciones de la producción agropecuaria que generaron excedentes por vía de las exportaciones de commodities. El despliegue del patrón de acumulación basado en el agronegocio produjo una modificación multidimensional del anterior modelo que articuló al sector agroexportador con el mercado interno. Esto se tradujo en un histórico superávit fiscal.

En una sociedad estructurada nuevamente por el consumo, el empleo público y la política social, los sectores dominantes vinculados a la producción sojera, cuya direccionalidad es la concentración económica, reubicaron su capital en el negocio inmobiliario y las inusitadas urbanizaciones de las principales ciudades del país - principalmente, en la región pampeana-. En la ciudad de Córdoba, el negocio inmobiliario coadyuvó a una alianza entre el sector público y privado 
que incrementó la mercantilización del suelo disponible e imprimió un carácter sociosegregador a la reconfiguración del escenario urbano cordobés. Al disponer políticas de vivienda para sectores populares, se relocalizaron familias de villas miseria ubicándolas en "ciudades-barrio", es decir, terrenos periféricos de menor valor comercial. Como síntomas de una sociedad clasista, las ciudades-barrio reprodujeron muros materiales y renovadas fronteras sociales —y racializantes- En este marco, el programa Mi casa, mi vida operó ideológicamente en las nuevas condiciones de habitabilidad para los sectores populares sometiéndolos a específicos mecanismos de represión y vigilancia policial.

Desde los años noventa, los sistemas productivos de las economías regionales — distintas a la producción de soja — entraron en periodo de crisis y retracción en contextos de transformación estructural de la agricultura. Lo anterior generó condiciones de pobreza en zonas periurbanas y rurales que fueron respondidas desde la focalización de políticas sociales. En la provincia de Chaco, como una de las provincias periféricas del noreste argentino, se enfatizaron los indicadores socioeconómicos alarmantes durante este periodo. No obstante, en la última década se suscitaron tres procesos heredados de la década del noventa en el centro-sur chaqueño: a) la tecnificación y reducción de la producción algodonera; b) la "pampeanización" de suelo productivo, introduciendo el cultivo de soja antes destinado al algodón —debido a la baja rentabilidad de este cultivo_-; c) y la consecuente reducción de la mano de obra tradicional de sectores indígenas y criollos del noroeste provincial en la agricultura —introduciéndose al mercado como consumidores por su condición de pensionados y beneficiarios de planes sociales. ${ }^{11}$

Como expresa Harvey (2004), uno de los mecanismos de acumulación a través de los cuales opera el nuevo imperialismo está basado en la desposesión respecto a las territorialidades campesinas, entre otras formas que adquiere la desposesión en las sociedades capitalistas actuales — cultural, intelectual, financiera-. En estas

${ }^{11}$ En un contexto de reprimarización de las economías regionales de Argentina, el incremento de la frontera agropecuaria a partir de la producción de soja fue acompañado por un aumento del desmonte legal e ilegal. Los datos para la campaña 2010 evidencian que en Chaco se sembraron 650,000 hectáreas de soja y 330,000 hectáreas de algodón (Barri, 2013). 
áreas rurales chaqueñas, en la actualidad y en simultáneo con la transformación de las estructuras agrarias, se viene registrando una creciente conflictividad por la tierra con la aceleración de hechos de violencia. Esta situación se profundiza en aquellas zonas donde se amplía la frontera agropecuaria mediante la incorporación de nuevas tierras a la producción de oleaginosas. En este sentido, se ha registrado en el campo argentino un creciente aumento en la magnitud de los indicadores de la violencia como dispositivo (des)territorializador en las áreas rurales (Domínguez y de Estrada, 2013). Paralelamente, la tierra se ha extranjerizado. De mismo modo, la mercantilización de las tierras céntricas en la ciudad de Córdoba también puede leerse como un eco de las formas de reproducción del capital que expulsa a las poblaciones asentadas en ellas mediante el accionar del Estado. En ese ángulo es que, a lo largo de este trabajo, sostenemos que en cada región la lógica de acumulación del capital asume características particulares, aunque combinadas.

En las últimas dos décadas, y en la provincia de Chaco en particular, la desigualdad imperante dada la expulsión de pequeños productores de zonas rurales y, luego, las fuertes intervenciones estatales, hicieron que las políticas sociales adquirieran subjetivamente el carácter de instituciones totales (Pérez Rubio, 2016). En el noroeste chaqueño, las localidades de Villa Río Bermejito, El Sauzalito y Misión Nueva Pompeya constituyen polos de nuevas urbanizaciones a la par de renovadas dinámicas socioeconómicas caracterizadas por: a) la implementación de políticas sociales y transferencias condicionadas; b) el incremento de migraciones, y c) el aumento creciente de las formas locales de consumo. En este marco, las políticas de vivienda espacializaron a los beneficiarios en torno a las plantas urbanas definiendo una localización céntrica según distintos argumentos técnicos y políticos (Quevedo, 2015). El Programa federal de mejoramiento de vivienda Mejor Vivir, en este caso, fue la política que diagramó una nueva cartografía de erradicación de viviendas-rancho. La política de hábitat social instituyó nuevas sensibilidades a partir de las lógicas de proximidades y distancias corporales — singulares en cada localidad- en las distintas poblaciones de El Impenetrable. 
Presentamos a continuación dos escenarios sociales para comprender la complejidad en la que opera el capitalismo como totalidad abierta. La fragmentación de los colectivos y la centralidad del consumo como mediadores sociales son los disparadores que proponemos pensar en sintonía con el capital y su reproducción actual como macrosignos musicales. La conflictividad social no puede analizarse sin escuchar melodías individuales que interpelan a los sujetos subalternos desde los espacios culturales del campo y de la ciudad: las matrices de urbanización mediante la segregación en una capital de las ciudades más populosas del país y los procesos de urbanización crecientes en contextos del monte chaqueño.

\section{"Mi casa, mi vida": las ciudades-barrio en Córdoba}

La experiencia de organización social borrada: la Mesa de Concertación de Politicas Públicas

Durante el periodo 1980-1994 se conformaron redes de asociación al interior de diversos asentamientos ubicados en la ciudad de Córdoba, a partir de las cuales se constituyeron cooperativas y mutuales orientadas a la promoción social y concretamente a tematizar el hábitat como cuestión social. En septiembre de 1992, cuatro ONG de la ciudad realizaron un taller al que concurrieron representantes de sesenta organizaciones de pobres urbanos de Córdoba, vinculados con el asesoramiento técnico. A partir de ese taller se fue constituyendo un colectivo que conformaría la Unión de Organizaciones de Base por los Derechos Sociales (UOBDS). En noviembre del mismo año comenzó a funcionar la Mesa de Concertación, espacio de diálogo entre representantes de la misma UOBDS — quienes hablarían por al sector de los pobres urbanos-, cuatro ONG y el Ministerio de Desarrollo Social de la Provincia de Córdoba. En julio de 1994, el Poder Ejecutivo Provincial firmó un decreto a través del cual se institucionalizaba el funcionamiento de la Mesa de Concertación, e incluyó en su presupuesto un rubro específico referido al funcionamiento de la Mesa (Aquín y González, 1998).

La Mesa de Concertación surgió como respuesta a las demandas de un sector que había conseguido instituirse como interlocutor frente al 
Estado. La administración provincial involucró a diversos actores de la sociedad civil en las instancias del proceso de concreción de respuestas en términos de políticas sociales, configurando un particular escenario de negociación. Según información de diversas ONG y un informe de Carlos Buthet (2007), en los 6 años de duración de la experiencia (1992-1997) se desarrollaron 270 proyectos en el campo del hábitat popular, que beneficiaron aproximadamente a 70 barrios $-7.000 \mathrm{fa}-$ milias, 35,000 personas.

Muchas cooperativas y mutuales lograron acceder a viviendas a través del financiamiento vía "Mesa", desde la modalidad de autoconstrucción por esfuerzo propio y ayuda mutua. Pero en el marco de la crisis provincial de 1997 y tras una violenta represión policial que culminó con algunos manifestantes ocupando la iglesia Catedral de la ciudad, la Mesa de Concertación fue cerrada. José Manuel De la Sota, candidato a gobernador por el justicialismo, había prometido su reapertura si resultaba electo, pero una vez gobernador en 1999 desconoció su promesa. Ya no volvió a abrirse ningún espacio para la discusión de las políticas sociales con los pobladores, redefinidos como "beneficiarios" de los programas. Si en gestiones anteriores al gobierno de De la Sota había aparecido la noción de "concertación" como manera de plantear la formulación e implementación de políticas públicas, en la nueva gestión la de "solidaridad" comenzó a definir las formas de intervenir sobre cuestiones sociales (Boito y Levstein, 2009).

\section{Mi casa, mi vida}

En materia de hábitat social, el gobierno provincial intervino significativamente a través del programa Mi Casa, mi vida, financiado por BID e implementado entre 2004 y 2009, a través del cual se construyeron más de 10,000 viviendas sociales. El plan implicó el traslado compulsivo de habitantes de villas ubicadas en terrenos céntricos y aledaños al centro de la ciudad de Córdoba hacia las denominadas "ciudades- barrio".

A partir del año 2003, el gobierno provincial implementó el "Plan de Emergencia para la Rehabilitación Habitacional de Grupos Vulnerables Afectados por las Inundaciones en la Ciudad de Córdoba”, 
mediante el cual se justificaba y generaba un marco para el programa Mi casa, mi vida. La escala de las urbanizaciones merece ser destacada: se construyeron barrios que en algunos casos contenían más de 500 viviendas; así como la localización relativa en relación con el centro de la ciudad. Los barrios se crearon en la periferia, en el mayor de los casos, fuera del tejido urbano (Núñez y Ciuffolini, 2011; Scarponetti y Ciuffolini, 2011).

De esta manera, el gobierno desechó la experiencia de las cooperativas y la autoconstrucción. Se relegó a los pobladores al rol de meros beneficiarios, de pasivos espectadores, excluidos de toda posibilidad de participación en el trabajo y decisión sobre la ubicación y características de sus nuevas viviendas y barrios. Sin embargo, la mayoría de los pobladores de los asentamientos aceptaron el traslado con gran esperanza y recibieron con alegría lo que se les presentaba como un "regalo" y un "sueño cumplido". El proyecto se presentó publicitariamente como "el techo de tus sueños". Esta expresión es un eslabón ideológico que implica también otro sentido: más que el acceso anhelado a la casa propia, significa ponerle un límite, un tope, a lo que estos sectores pueden "soñar" en cuanto a habitar la ciudad cordobesa.

En el mismo acto se fueron disponiendo los espacios de las antiguas urbanizaciones en zonas "recuperadas" para las inversiones inmobiliarias. Así, esta política benefició a los más grandes grupos empresariales de la construcción, que en muchos de esos espacios desalojados erigieron edificios, centros comerciales, $\mathrm{u}$ otras opciones habitacionales para las clases medias y altas. Algunos de estos grupos participaron también en la construcción de los planes habitaciones, integrando a las Uniones Transitorias de Empresas (UTE). La alianza Estado-Mercado se plasma de esta manera en la reconfiguración de la cartografía de la ciudad. 

de vivienda para sectores subalternos...

Figura 1. Cartografía de ciudades-barrio y complejos privatizados en la ciudad de Córdoba (2010).
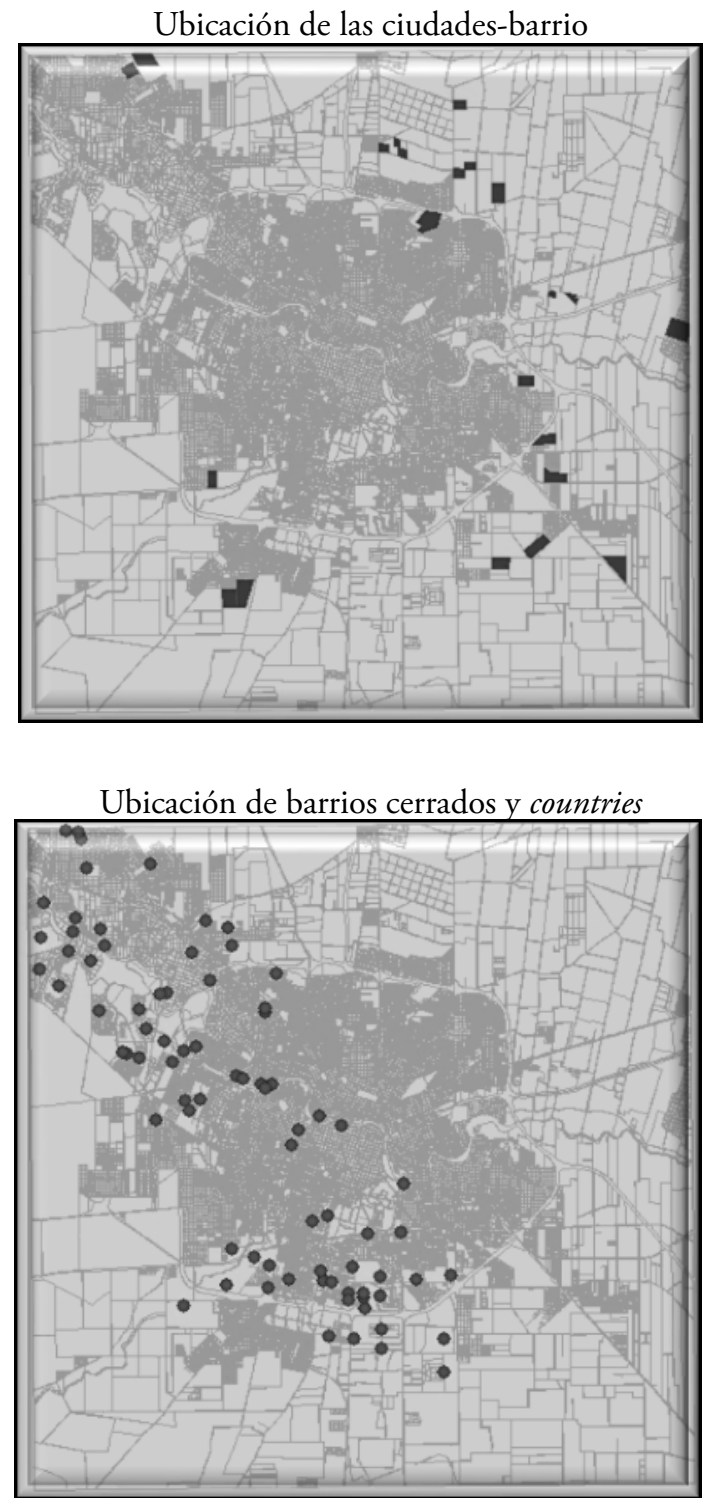

Fuente: Elaborado por Pedro Matías Lisdero 
Figura 2. Viviendas construidas en el marco de Mi casa, mi vida.

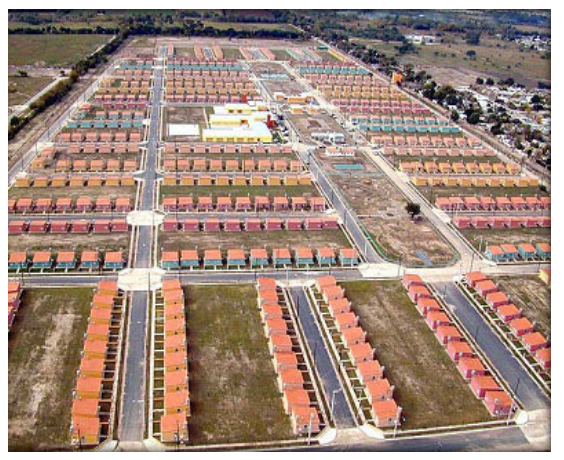

Portales que delimitan el adentro y el afuera de cada barrio-ciudad
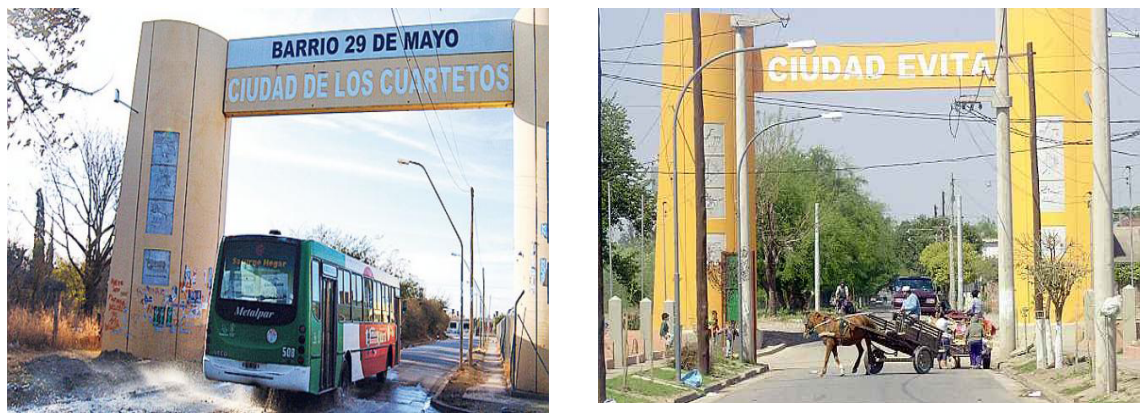

Fuente: ${ }^{12}$ (1) Café de las ciudades; (2) Día a día; (3) La Voz del Interior

Ser joven en las ciudades-barrio

La indagación requiere detenerse en las estructuras del sentir de los ciudadanos/consumidores forjados en la década analizada al anclar cuerpo/clase a espacios concretos. Como ya dijimos, en la presentación oficial esta política urbana, la adjudicación de la vivienda, se presentaba como "El techo de tus sueños". Los jóvenes como grupo etario fueron los primeros en vivenciar la materialidad de la pesadilla que encierra

\footnotetext{
${ }^{12}$ De arriba abajo y de izquierda a derecha: 1) disponible en http://www.cafedelasciudades. com.ar/planes_normativas_73.htm; 2) disponible en http://www.diaadia.com.ar/content/ciudad-de-mis-polemicas-por-los-barrios-ciudades-0; 3) disponible en http://archivo.lavoz.com. ar/anexos/imagen/09/135990.jpg. Publicadas en María Eugenia Boito y Emilio Seveso Zanin, 2015, La tecnología como ideología en contextos de socio-segregación. Ciudades-barrio (Córdoba, 2011-2014), editorial Puńo y Letra, Rosario, Argentina, p. 17.
} 
la publicidad oficial. Desde que llegaron a los barrios-ciudad, los más jóvenes han sido y son continuamente desalojados de diversos escenarios: de las escuelas, de posibles empleos cuando informan su domicilio — que aparece como estigmatizante - y hasta de las mismas viviendas que no tienen espacio para ellos $-42 \mathrm{~m}^{2}$ para familias de un promedio de seis personas por hogar.

Uno de los jóvenes entrevistados en Ciudad de Mis Sueños mencionó al ser consultado en durante el trabajo de campo: "Mi sueño es tener una habitación para mí, con techo de material y televisor" (M., entrevistado en Ciudad de Mis Sueños, 2013). Dentro de otras narrativas juveniles, a partir de la frase advertimos que los jóvenes no tienen lugar en el barrio ni en sus casas, porque han crecido más rápido que las posibilidades colectivas de albergarlos. La expulsión es la condición experiencial permanente para este grupo. No se reduce al espacio/tiempo del traslado hacia las nuevas urbanizaciones, sino que en sus trayectorias vitales se constata esa errancia como vivencia traumática que se actualiza en el desplazamiento hacia el centro de la ciudad. Los programas de seguridad les impiden ese retorno mediante la aplicación permanente del Código de Faltas. La movilidad reducida que marca la cotidianeidad del grupo puede ser representada mediante grafía de un "círculo de encierro", o lo que es lo mismo, un "entorno de clase” (Boito y Seveso Zanín, 2015). La geometría de los desplazamientos encuentra en la figura del círculo la condensación que ilustra la movilidad disminuida en espacios de constricción de la acción. La siguiente nota de campo amplia lo expresado:

Ciudad Evita fue la primera ciudad barrio. El mapa del nomenclador no coincide con las formas y las dinámicas de los territorios de la urbanización, no sólo por "errores" del cartógrafo sino porque en la entrada hay construcciones precarias nuevas. Casas de madera en su mayoría construida por parejas jóvenes en el borde de los bordes de estos escenarios de la relegación social.

L. me esperaba cuando llegué a su casa. De sus hijos, dos viven ahí y otros dos alquilan en el barrio San Lorenzo que se encuentra próximo, 
pasando el arco de entrada que marca el ingreso al barrio-ciudad. "Éste no es un lugar para los hijos", me dice, como me lo dijeron ya tantas veces, haciendo un solo lamento colectivo de una generación de pobres que cuando "entró" a la casa. Cuando se hizo realidad "el techo de los sueños" sintió de manera ambivalente que llegó a un lugar que ya lo expulsaba, o del cual los hijos tenían que salir. En todas las urbanizaciones la compra y venta de las casas no fue una excepción sino una tendencia relevante (Ciudad Evita, inaugurada el 19 de mayo de 2004; nota de campo de abril de 2013).

En investigaciones anteriores ciertos ejes temáticos se revelaron como recurrentes: la obtención de la casa propia como momento fundacional; el recuerdo de la lucha y el trabajo colectivo previos; y el contraste con las dificultades que encuentran actualmente los jóvenes del barrio para organizarse. Los padres de los jóvenes manifiestan una profunda preocupación y tristeza cuando anticipan las posibilidades de acceso a una vivienda para sus hijos. La nueva generación no cuenta con la antigua experiencia de UOBDS. En algunos casos no ha sido transmitida de generación en generación como prácticas concretas y de clase, a partir de las cuales se marca el horizonte de expectativas y posibilidades; y en otros, encuentra profundas dificultades socioorganizativas para actualizarse por la pérdida de lazos de comunalidad.

La expresión del conflicto en tanto vivencia del malestar puede ser divisado dentro de una idea de totalidad, basada en la tensión entre expectativas sociales y posibilidades expresivas. Allí es donde la tecnología - el sueño de la habitación propia con televisor - se trama en un conjunto de nuevos artefactos que prometen comunidad y salida de los círculos de encierro: el uso del celular aparece en relación con la escena del "hogar" y la imposibilidad de movilidad de los cuerpos (Williams, 2011; Boito y Seveso Zanin, 2015). En un contexto de fragmentación y privatización de la vida, la distancia cultural dificulta la experiencia colectiva en estas generaciones. Aun entre quienes portan expectativas de "progreso" éste es individual y se materializa en mejoras de las viviendas en los contextos de sociosegregación expuestos. Para el resto, opera la fantasía de lo tecnológico en la tendencia a una 
constante personalización de los dispositivos y de sus innovaciones. Pues, la tecnología también opera como ideología en los contextos de segregación urbana.

\section{"Mejor Vivir": casas-caja para pueblos indígenas}

Las casas-caja en zonas rurales de Chaco

En 2004, la provincia de Chaco es una de las que firma el Convenio Marco Programa Federal de Mejoramiento de Vivienda. La iniciativa en materia de hábitat social se implementa desde el Ministerio de Planificación Federal, Inversión Pública y Servicios, y los gobiernos provinciales a través de los Institutos provinciales de vivienda - en caso de Chaco corresponde al Instituto Provincial de Desarrollo Urbano y Vivienda, IPDUV_- Se propuso en esfuerzo asociativo entre el Estados nacional, provinciales y municipales tendientes a la reactivación económica. Mediante ese convenio, el programa de mejoramiento de viviendas Mejor Vivir, MV, implementó planes "solidarios" o subsidios no reintegrables por el beneficiario. Tenían por objeto la terminación, refacción y ampliación de viviendas para grupos familiares sin acceso al crédito y estuvo dirigido al "mejoramiento" de viviendas deficitarias recuperables.

Desde el año 2005, el Programa Federal de Mejoramiento de Viviendas Mejor Vivir fue el más extendido en esta provincia a partir de la administración de IPDUV, particularmente en las localidades de El Impenetrable. La construcción y administración de los planes de vivienda asignados queda en manos de los municipios - eventualmente hay "convenios con municipios"- o, en ocasiones, es el Instituto de vivienda quien lo ejecuta a través de licitaciones públicas. En ambos casos, la elaboración de las listas de posibles beneficiarios, según los requisitos, o la toma de decisiones en torno a la elección de los destinatarios queda en manos de cada municipio según la cantidad de "soluciones" disponibles. Estas respuestas habitacionales eran módulos y consistían en una habitación y un baño afuera - a veces consideraban una galería-. En un primer momento, tenían un costo oficial de $\$ 10,000$ — pesos argentinos-y una dimensión de 3 por $4 \mathrm{~m}^{2}$.

Si bien existieron otras políticas focalizadas para "aborígenes" en la década analizada, en la práctica el programa habitacional MV —en sus 
distintas versiones - fue el que más cantidad de módulos otorgó a familias indígenas. Además enfatizó el sentido del "mejoramiento" del hábitat presuponiendo el respeto a relaciones sociales y entornos de los sujetos. Así, la "casa-caja” se construyó en toda la región de El Impenetrable como viviendas en sí mismas —es decir, el módulo prescindió de vivienda previa - y localizándose en los centros más poblados de cada municipio. De este modo, en las poblaciones chaqueñas en cuestión, la política de hábitat social cristalizó tres mecanismos técnicos de regulación poblacional en niveles locales: en primer lugar, quedó en manos de la familia beneficiaria ampliar o construir habitaciones o reparos al lado de la "casa-caja" dado que enfatizaban un modelo de "familia nuclear" —y no basado en "familias extensas", como es la matriz de sociabilidad indígena en estas regiones_- en segundo lugar, dispersó a las familias siendo que el municipio parceló nuevos terrenos en áreas urbanizadas — con el argumento técnico de la economía de los recursos públicos que, en ocasiones, dieron origen a nuevos barrios o grupo de viviendas-; y en tercer lugar, supuso criterios de distribución y de localización física de las viviendas según las propias matrices de pertenencia y diversidad de cada municipio - comunidades compuestas por categorías clasificatorias nativas como las de "indígenas/aborígenes", "criollos" y "gringos/blancos"- - A su vez, estos criterios están atravesados por tradicionales formas de clientelismo, negociación y, a menudo, de discriminación social.

Imagen 1. Casas-caja en una de las localidades de El Impenetrable, Chaco.

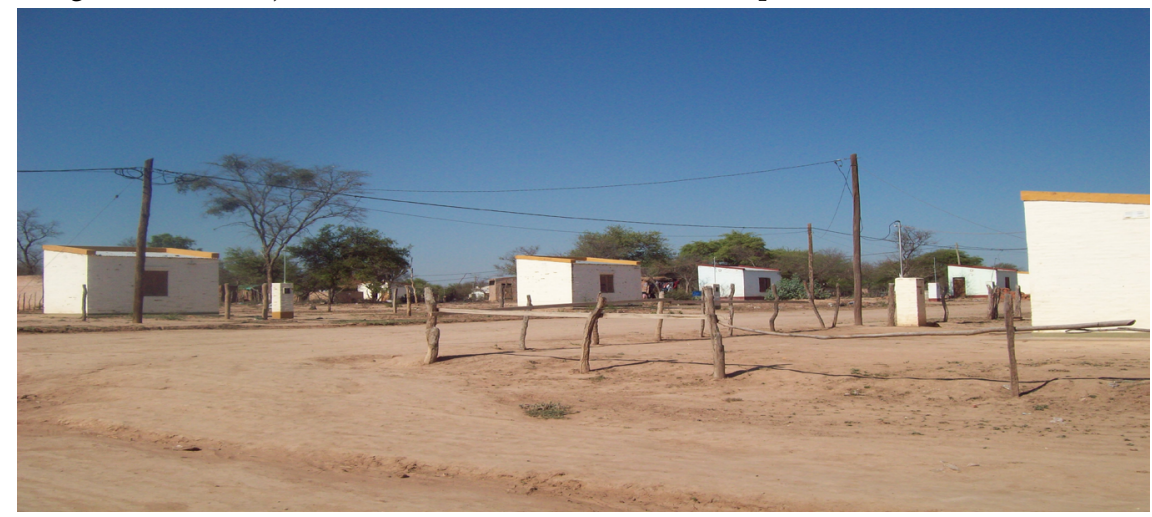

Fuente: fotografía de las autoras 


\section{Casas-caja: el discurso politico de la "reparación histórica"}

A partir de 2007, con la asunción de Jorge Capitanich como gobernador de la provincia de Chaco, emerge un discurso político que articuló a través de formas redistributivas procesos de reconocimiento a las alteridades indígenas — de los pueblos qom, wichí y moqoit — con retóricas basadas en la dignificación social mediante el recurso de la vivienda. Lo que se conoció en la nueva hegemonía provincial fue discurso de "reparación histórica a los Pueblos Originarios". De este modo, se pone en evidencia el lugar prioritario y las formas de visibilización de la alteridad indígena en el nuevo gobierno chaqueño. Consideramos que el discurso neoindigenista provincial supuso que el otorgamiento de vivienda estaba sustentado la dignidad del sujeto reconocido culturalmente en su diferencia. Dentro del universo de significación peronista, el valor de la dignidad ya no estaba asociado a su integración a la sociedad mediante el trabajo: lo que dignificaba era el otorgamiento de la vivienda. El acceso a "vivienda digna" por parte de los indígenas fue incuestionado tanto como promovido: la vivienda no sólo es don del Estado sino también un fetiche de la época que suspende o niega los antagonismos sociales - la lucha por la tierra, por ejemplo- Al mismo tiempo, aunque se debilitó el énfasis en la erradicación de viviendas-rancho por la epidemia del Mal de Chagas operaron los mismos mecanismos sanitaristas y los modelos de asepsia social que regían desde varias décadas previas. Estos presupuestos continuaban cuestionando la idea de la "familia extensa" indígena reproducida en ámbitos urbanos.

El Fondo Federal Solidario, implementado como Decreto 206 de 2009 por el Gobierno Nacional, tuvo como objetivo distribuir entre las provincias $30 \%$ de lo que el Gobierno recauda en concepto de retenciones a la exportación de soja. Pues, otra de las maneras en que las políticas a partir de los excedentes de la sojización afectaron a estas poblaciones en el medio de El Impenetrable fue a través del denominado "fondo sojero". Por ejemplo, en el caso del Municipio El Sauzalito, el fondo estaba destinado en su totalidad a la construcción de letrinas para la población indígena —wichí-. El valor de la "solidaridad" con la que se significaba el plan de vivienda — al igual que en la ciudad de Córdoba-, al ser reemplazado por MV, es enfatizado por 
la distribución de fondos a regiones marginales mutando en, a través de Estados locales, mecanismos que profundizaban discursivamente el "mejoramiento" ya iniciado por la casa-caja.

\section{La urbanización: juventud indígena y el deseo de movilidad}

La entrevista realizada a un técnico del Instituto de vivienda chaqueño dedicado al hábitat para pueblos indígenas es una pieza clave para comprender la operatoria del nuevo régimen de sensibilidad. En el diálogo, se relaciona la nueva vivienda otorgada a "la moral del mejoramiento" en la provincia de Chaco. En este sentido, el funcionario de IPDUV comenta que en sus viajes desde la ciudad capital de la provincia - ciudad Resistencia - a las distintas localidades del "interior", y en calidad de no-indígena, proporcionó "consejos" para evitar conflictos entre las familias beneficiadas. Narra sobre el deber ser del "buen vecino" a partir de la adjudicación de vivienda MV y de las nuevas urbanizaciones consecuentes. Estas expresiones son un disparador para indagar en los sentires de la juventud y su experiencia dentro de nuevas condiciones de habitabilidad. En palabras del técnico:

Yo me junto con la comunidad [indígena], como son barrios por ahí, viste, se forman barrios con 10 viviendas, 15 viviendas, yo sé su forma cultural pero eso ya no tiene mucho que ver con la forma cultural sino con la forma de convivencia. Entonces trato de hacerles entender que la música fuera de horario ya molesta al vecino, que me parece bien que estén contentos, que estén felices y que lo expresen me parece perfecto, pero hay que tener un poco también de cordura y cuidado con la bebida, porque los chicos te están viendo, no se olviden de sus hijos porque ellos son el futuro, ustedes tiene que luchar por... yo todo un mensaje trato de dejarlo siempre que puedo con ellos, viste, cuando estoy reunido (entrevista a funcionario de IPDUV de "vivienda aborigen”, 2011, ciudad Resistencia, Chaco).

Tener una vivienda estatal implica, para la perspectiva moral de los representantes del Estado provincial, que el indígena debe cambiar "su manera de ser". La vivienda y el nuevo entramado de viviendas es 
una suerte de rito de pasaje a un mundo civilizado sin "música fuera de horario" y con "cordura y cuidado con la bebida". Como expresa Williams, "erigir una familia" implica ante todo "consolidar y mejorar las propiedades familiares" (2001: 96). De esta forma, construye al estereotipo del "indígena" en estas regiones: un borracho y marginal al que hay que disciplinar estatalmente. La moral del mejoramiento, que se imprime en el otorgamiento de la casa-caja y se torna objeto de prédica por parte de los agentes estatales, restituye el orden silencioso de sujetos inaudibles: "las voces bajas" como características de las clases subalternas. Pero la entrevista al técnico da cuenta no sólo de que las transformaciones están sostenidas en las urbanizaciones de familias nucleares sino también en el estado de felicidad social — "que estén contentos, que estén felices y que lo expresen"- por el acceso a los bienes del mercado por parte de un sujeto indígena con mayores posibilidades de consumo.

Un punto de conflicto de la política pública habitacional que, en la materialidad de las relaciones sociales a nivel local, es la dicotomía sobre si la vivienda urbaniza a las comunidades indígenas o si las comunidades indígenas ya estaban urbanizadas cuando se le construyó sus viviendas. En torno a esta tensión operan los nuevos incentivos o fetiches para la vida cotidiana en las plantas urbanas, territorialidades que hasta hace pocos años eran unos tranquilos puñados de casas agrupadas en el medio del monte: los procesos de mercantilización de la experiencia a través de las nuevas formas de consumo en almacenes, supermercados y locales de bazar.

Uno de los antropólogos que en los años setenta teorizó sobre los indígenas de Chaco fue Elmer Miller, autor de Los tobas argentinos: armonía y disonancia en una sociedad (1979). Utilizando metáforas musicales proponía explicaciones a las rupturas con el entorno natural causado por la colonización y la violencia militar. El autor también refería al intento en restituir los desequilibrios culturales vía prácticas religiosas y, a partir del pentecostalismo desde los ańos cuarenta, de las nuevas expectativas festivas y salvacionistas. En la actualidad, a contrapelo del lamento y la incomodidad de la vida como vecino del criollo, el equipo de música, el alcohol, la moto o la diversión 
son los nuevos horizontes de deseabilidad que suturan formas de dolor y añoranza de un contexto de monte que se perdió y una modernización de lo rural que nunca llega del todo. Detengámonos en una conversación con Julio, 24 años, vecino wichí de El Sauzalito, cuya familia es beneficiaria de una casa-caja:

Julio (J): también pasa que hay algunos que tienen casas hermosas, tienen todo-todo y después se van porque dicen, por ejemplo... cuando tienen vecinos blancos así, empiezan a irse... como... que se sienten incómodos... como la familia de Hugo... ¡te acordás?, y miles de veces le dieron vivienda y cada vez que había un vecino blanco así se iban... y cada vez se agrandaba el pueblo y llegaban al monte y se cambiaban, y así, todo el tiempo... no sé cuál es la cuestión, como que se siente observado por los blancos... por ahí dicen "para qué voy a tener casa linda si nos morimos de hambre, o no tenemos lo que ellos tienen".

Entrevistadora (E): ¿y qué es lo que ellos tienen que te gustaria tener a vos? J.: y... la moto para ir a ver a mis familiares que viven en la otra punta, mis primos. Tenía, se rompió...

E: ¿tus primos?

J.: Sí, están en la joda todavía. Me gusta ir porque tiene sus amigos ahí, escuchan música a la noche, toda la noche.

Las profundas transformaciones a partir de las políticas sociales han posibilitado que la juventud indígena consuma mercancías muy variadas. La moral del mejoramiento es puesta en cuestión y resistida a partir del abandono o la venta del módulo habitacional. En ocasiones, ni siquiera el tener materialmente "todo-todo" frena el dinamismo de la forma de vida indígena, el deseo de no vivir al lado del "criollo" o, por un instante, poder movilizarse en motocicleta para evadirlo. En los jóvenes la experiencia del consumo, al mismo tiempo que los separa de los más ancianos en su grupo de pertenencia - aquellos que quieren irse del lado del "blanco"- al mismo tiempo los vincula a nuevas formas de comunalidad. La construcción de entornos donde 
la familia, la música ${ }^{13}$ y la tecnología — aun en iglesias evangélicas, en boliches, en las esquinas oscuras de los barrios iluminados por celulares - o el alcohol son lo que morigeran las angustias y las nuevas desigualdades materiales. La homogeneización cultural como lo otro de la "reparación histórica" demuestra que hasta las armonías y las disonancias han cambiado en esta parte del Chaco: como si se tratara del sonido estridente de algún instrumento de viento, la vivienda no "repara" sino que desgarra relaciones sociales precedentes.

Imagen 2. La casa-caja y las motos como signos de época en El Impenetrable.

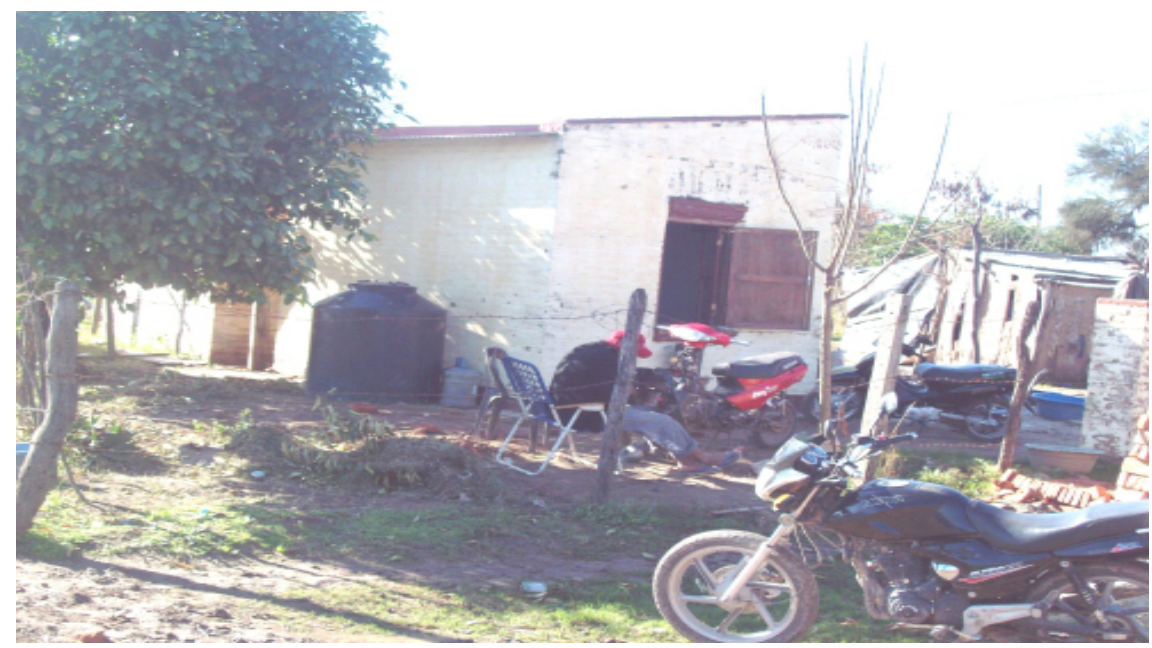

Fuente: fotografía de las autoras

\section{Coda. El progreso de los pobres: señuelo ideológico y violencia de clase}

I. En este escrito hemos comparado dos enclaves provinciales en cuanto a producción ideológica de la vivienda social para sectores subalternos: las ciudades-barrios y los procesos de urbanización en casas-caja. Para dar cuenta de las dinámicas de la política de vivienda

\footnotetext{
${ }^{13}$ En este punto establecemos un paralelismo sobre el consumo de música en las ciudades-barrio de Córdoba. "Como entorno tecnológico cada vez más pegado al cuerpo, la escucha se define como transporte en diversos sentidos: lleva a otros tiempos, a otros lugares y también cambia el ánimo. Traslada también hacia 'otro mundo', distrayendo del presente y sus problemas..." (Boito y Seveso Zanin, 2015: 165).
} 
en su faz hegemónica trabajamos en dos provincias con distintos niveles de desigualdad social y tramas productivas. Nos referimos a la provincia de Córdoba, deteniéndonos en ciudad capital, y a la de Chaco, observando al departamento General Güemes — región conocida como "El Impenetrable" - de características poblacionales tradicionalmente rurales. Como resultado deconstruimos el locus de la política de vivienda dentro de un proceso de ampliación espacial de la agricultura capitalista a gran escala y de retóricas inclusivas de las políticas de hábitat social para sectores populares. El argumento del trabajo consideró que el otorgamiento de la vivienda social se instituye como "seńuelos ideológicos" (Žižek, 2009) mediante lo que denominamos "la moral del mejoramiento" (Williams, 2001).

Las experiencias sociales en dos lugares específicos distintos/ distantes conjugan puntos en común en tanto resultante de una misma lógica del capital. Concluimos que, dentro de las complejas dinámicas de destrucción/construcción de reproducción capitalista (Harvey, 2004), encuentra en relación entre el campo y la ciudad los mismos desplazamientos, aunque con características particulares respecto a centros urbanos: movimientos centrífugos para la ciudad de Córdoba y centrípetos para las regiones rurales de la provincia de Chaco. En este sentido, si la construcción territorial de las catorce ciudades-barrio cordobesas fue la manera en que el Estado configuró mecanismos de expulsión de ciertos sectores hacia las periferias de esa ciudad, en el caso chaqueño la urbanización tendió a la centralización de las poblaciones indígenas ahora reconocidas oficialmente.

La fragmentación de los colectivos y la centralidad del consumo son mediadores que propusimos para inquirir en las intervenciones habitacionales. En sintonía con la reproducción actual del capital, fueron interpretadas como "macrosignos musicales" de evitación de la conflictividad social en los escenarios contemporáneos. Los discursos basados en "el techo de tus sueńos" y en "la reparación histórica" constituyen eslabones ideológicos de violencia ética respecto a sectores subalternos. Por esto la coda, a modo de epílogo, utiliza o retoma los primeros movimientos de la forma de regulación de las sensibilidades sociales evidenciada, en vistas de legitimar la operatoria de ambos 
programas habitacionales tanto para sus destinatarios como para el resto de los pobladores de las ciudades y de los campos.

Los patrones de dominación son obturados por la operatoria de formas de interpelación que se sostienen en visiones y divisiones del mundo organizadas desde una mirada universalizante. Pero esos patrones siempre son vivenciados a través de las estructuras del sentir, es decir, como recuerdo, presente y proyección de expectativas que portan los sujetos. Estas estructuras del sentir enmarcan a las prácticas posibles/deseables en horizontes simbólicos como espectro de libertad y constricción de la tematización de las acciones, así como también de las formas y límites de sus posibilidades expresivas. La referencia a ciertas vivencias de los jóvenes - de lamento o de ensoñación en ambos escenarios - tajea "la moral del mejoramiento". En efecto, en el trabajo aludimos a las limitaciones de los procesos de libertad y emancipación en tiempos democráticos, ya señalados por Engels (2007) en el clásico escrito sobre "el problema de la vivienda". Resta para futuras indagaciones un análisis comparativo sobre el lugar de las viejas/nuevas tecnologías en ambos entramados sociales y el anclaje ideológico —y de "ensueño"— del vínculo entre técnica/sensibilidad.

II. Žižek refiere a las analogías musicales nada menos que en la estructura de su libro Sobre la violencia. Seis ensayos marginales (2009). En un sentido nuestro escrito pretendió estetizar la escritura, pero retomando el sentido etimológico de esta noción: la estética como lo que percibe el cuerpo a través de las sensaciones. Y esto se relaciona con la opción por la analogía musical en el ejercicio de escritura científica; semejanza que, en los casos abordados, posibilita escuchar los sonidos de la destrucción cuando pornográficamente ésta se muestra, se dispone ante nuestros ojos, aunque no nos percatemos de ella.

La referida analogía también posibilita mostrar como continuum lo que aparece como separado o fragmentado. ¿Pero hasta qué punto este continuum conduce a una indiferenciación entre lo urbano y lo rural en términos de experiencia social? En este sentido, el trabajo postula líneas de diálogo con otros de la sociología urbana que debaten la reproducción o la reconfiguración de la tensión campo/ciudad: "el 
carácter excluyente de la producción capitalista del espacio social se generaliza en los campos y en las ciudades" (Limonad y Monte-Mór, 2012: 13). Se trata de un ejercicio de montaje para reunir las partes de un universo unificado por el avance de la lógica del capital. En este momento de transformación de los roles del Estado, cada vez más orientados a garantizar el avance de los grandes grupos empresariales, el análisis en clave ideológica de los modelos productivos visibiliza estrategias de inclusión habitacional en territorios neocoloniales. En este punto radica la pertinencia de utilizar marcos analíticos que enfaticen lo ideológico y el carácter estructurador del conflicto sobre experiencia y sensibilidad en espacios heterogéneos.

III. Tal como exponen en imágenes los miembros del Club de Investigaciones Urbanas y la Revista Crisis en el filme sobre la ciudad de Rosario - Argentina - titulado Ciudad del Boom, Ciudad del Bang, ${ }^{14}$ el monocultivo sojero y el "Boom" de la construcción son la misma cara en la que se traman campo y ciudad: una ciudad de casas vacías, cajas fuertes de la soja que retorna como ladrillos; una ciudad de casacaja que destruye las formas asociativas presentes y la experiencia de estar juntos que se trasladaba de generación en generación y anclada en la tierra. La musicalización del documental rosarino sigue el cruento "orden" que hace circular mercancías/dinero/mercancías entre campo/ ciudad. En nuestro caso, la cruel melodía da cuenta de la alienación que día con día los habitantes de la ciudad vivencian como trabajadores de la construcción ante "mercancías" por siempre alejadas cuando se termina su quehacer como obreros. La mercancía "vivienda" como imposible de ser apropiada, aunque coexistiendo con otras más accesibles que se les ofrecen. Las motocicletas, por ejemplo, les permiten habitar la fantasía de ser consumidores no fallidos.

El "Bang" del filme y de nuestro escrito es la resultante sonora de múltiples procesos: el sonido más recurrente de ciudades sitiadas a partir de haber resituado en los bordes a los miembros de sus clases subalternas. El "Bang" como sonido de encendido también resuena en la ideología de consumidor vuelta materia — la motocicleta, el

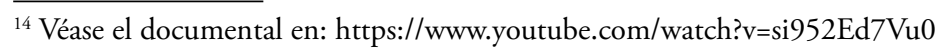


televisor o el teléfono celular- por la que se sienten interpelados tanto los jóvenes chaqueños como los cordobeses, huyendo aceleradamente pero en el marco de los círculos de encierro que hemos identificado. El "Bang" como sonido tiene intensidades y modulaciones varias. Esperamos que el registro de estas voces encuentre alguna condición de escucha, ante un tipo de estructura de la experiencia que, de manera recurrente y permanente, se va moldeando desde la ceguera/sordera entre clases sociales.

\section{Bibliografía citada}

Aquín, Nora y Cristina González, 1998, Mesa de concertación de políticas sociales. ¿Modelo para replicar?, Espacio Editorial, Buenos Aires.

Barri, Juan Manuel, 2013, "Los campesinos chaqueños en la encrucijada", Estudios Rurales, núm. 4, pp. 15-39.

Boito, María Eugenia, 2010, "Estados de sentir en contextos de mediatización y mercantilización de la experiencia. Intentos por precisar una lectura materialista de las sensibilidades", en J. L. Grosso y M. E. Boito (compiladores), Cuerpos y emociones desde América latina, CEA-CONICET, Córdoba, pp. 82-101.

Boito, María Eugenia y Ana Levstein (compiladoras), 2009, De insomnios y vigilias en el espacio urbano cordobés: lecturas sobre "Ciudad de mis sueños", Jorge Sarmiento Editor, Córdoba.

Boito, María Eugenia y Emilio Seveso Zanin, 2015, La tecnología como ideología en contextos de socio-segregación. Ciudades-Barrio (Córdoba 2011-2014), Puño y Letra, Rosario.

Boito, María Eugenia y María Belén Espoz (compiladoras), 2014, Urbanismo Estratégico y Separación clasista. Instantáneas de la ciudad en conflicto, Puño y Letra, Rosario.

Domínguez, Diego y María de Estrada, 2013, “Asesinatos y muertes de campesinos en la actualidad argentina: la violencia como dispositivo (des)territorializador", Astrolabio, núm. 10, pp. 489-529.

Espoz, María Belén, 2013, Los "pobres diablos"en la ciudad colonial. Imágenes y vivencias de jóvenes en contextos de socio-segregación, Estudios Sociológicos, Buenos Aires. 
Espoz, María Belén e Ileana Ibañez, 2008, “Subjetividades en contextos de pobreza: aportes a una metodología expresivo creativa para re-inscribir prácticas de niños/as y jóvenes de Ciudad de mis sueños", Perspectivas de la comunicación, vol. 1, núm. 2, pp. 72-83.

Gras, Carla y Valeria Hernández, 2009, La Argentina rural. De la agricultura familiar a los agronegocios, Biblos, Buenos Aires.

Grüner, Eduardo, 2009, "Prólogo. Sobre el estado-bifurcación y otras perplejidades dialogantes", en Judith Butler y Gayatri Spivak, ¿Quién le canta al estado-nación?: lenguaje, politica, pertenencia, Paidós, Buenos Aires.

Harvey, David, 2004, El nuevo imperialismo: acumulación por desposesión, Akal, Barcelona.

Herzer, Hilda (compiladora), 2012, Barrios al sur. Renovación y pobreza en la Ciudad de Buenos Aires, Edición Café de las Ciudades, Buenos Aires.

Lefebvre, Henri, 2011, "La noción de totalidad en las ciencias sociales", Telos, vol. 13, núm. 1, pp. 105-124.

Limonad, Ester y Roberto Monte-Mór, 2012, "Por el derecho a la ciudad, entre lo rural y lo urbano", Scripta Nova, Revista electrónica de geografía y ciencias sociales, vol. XVI, núm. 418 (25), pp. 1-15.

Miller, Elmer, 1979, Los tobas argentinos. Armonía y disonancia en una sociedad, Siglo XXI, México.

Núñez, Ana y Alejandra Ciuffolini (compiladoras), 2011, Política y territorialidad en tres ciudades argentinas, El Colectivo, Buenos Aires.

Oszlak, Oscar, 1991, Merecer la ciudad. Los pobres y el derecho al espacio urbano, CEDES, Buenos Aires.

Pérez Rubio, Ana María, 2016, "Las políticas sociales como instituciones totales: la construcción de la subjetividad", en A. M. Pérez Rubio y P. Barbetti (compiladores), Politicas sociales: significaciones y prácticas, Estudios sociológicos, Buenos Aires, pp. 71-90.

Quevedo, Cecilia, 2015, Estados locales y alteridades indigenas. Sentidos sobre la inclusión habitacional en El Impenetrable, Tesis de doctorado, Centro de Estudios Avanzados, Universidad Nacional de Córdoba, 28 de octubre de 2015, Córdoba. 
Sarlo, Beatriz, 2001, "Prólogo", en R. Williams, El campo y la ciudad, Paidós, Buenos Aires.

Scarponetti, Patricia y Alejandra Ciuffolini (compiladoras), 2011, Ojos que no ven, corazón que no siente. Relocalización Territorial y conflictividad social: un estudio sobre los barrios ciudades de Córdoba, Nobuko, Buenos Aires.

Scribano, Adrián y Maria Eugenia Boito, 2010, "La ciudad sitiada: una reflexión sobre imágenes que expresan el carácter neocolonial de la ciudad (Córdoba, 2010)", Actuel Marx Intervenciones, núm. 9, pp. 239-260.

Svampa, Maristella, 2008, Cambio de Época. Movimientos sociales y poder politico, Siglo XXI, Buenos Aires.

Williams, Raymond, 2000, Marxismo y Literatura, Península, Barcelona. Williams, Raymond, 2001, El campo y la ciudad, Paidós, Buenos Aires. Williams, Raymond, 2011, Televisión: tecnología y forma cultural, Paidós, Buenos Aires.

Žižek, Slavoj, 2009, Sobre la violencia. Seis ensayos marginales, Paidós, Buenos Aires.

Páginas web consultadas

Buthet, C., 2007, "Politicas públicas de vivienda social y derecho a la ciudad", XIII Encuentro ULACAV, V Jornada Internacional de Vivienda Social, 10-13 de octubre de 2007, Santiago, Chile, disponible en http://www.invi.uchile.cl/derechociudad/ponencias/Jornada/ Panel\%202/BUTHET,\%20CARLOS_J1.pdf [Fecha de consulta: 20 de mayo de 2010 (ahora ya no esta disponible)].

Céspedes, Martín, 2013, Ciudad del Boom, ciudad del Bang, Club de Investigaciones Urbanas y la Revista Crisis, Rosario, Argentina, disponible en https://www.youtube.com/watch?v=si952Ed7Vu0 [fecha de consulta: 28 de junio de 2016].

Engels, Friedrich, 2007 [1873], "Contribución al problema de la vivienda", disponible en http://www.archivochile.com/Ideas_ Autores/engelsf/engelsde00018.pdf 